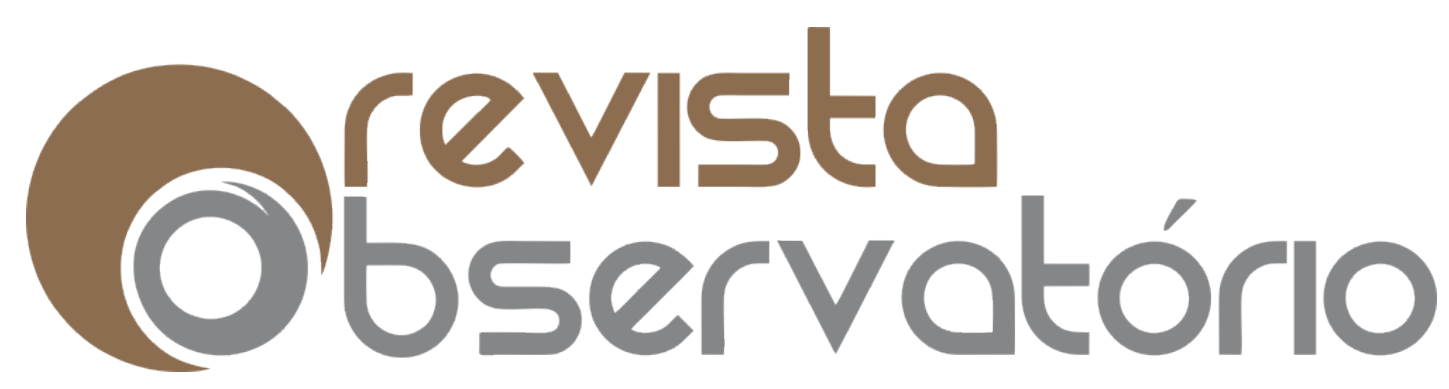

ISSN n² 2447-4266

Vol. 5, n. 5, Agosto. 2019

DOI: http://dx.doi.org/10.20873/uft.2447-4266.2019v5n5p111

\section{EXPOSIÇÃO DE SI NOS AMBIENTES DIGITAIS E OS DESAFIOS NA COORDENAÇÃO DAS REGRAS DE PRIVACIDADE}

EXPOSURE OF DIGITAL ENVIRONMENTS AND CHALLENGES IN THE COORDINATION OF PRIVACY RULES

EXPOSICIÓN DE SI EN LOS AMBIENTES DIGITALES Y LOS DESAFÍOS EN LA COORDINACIÓN DE LAS REGLAS DE PRIVACIDAD

\author{
Rodrigo Nejm ${ }^{1}$ \\ José Carlos Ribeiro ${ }^{2}$
}

\title{
RESUMO
}

Este trabalho apresenta uma breve discussão sobre os atuais desafios na coordenação dos limites da privacidade nos ambientes digitais, numa dimensão plural, com destaque à dimensão informacional, relativa ao fluxo de informações pessoais nas interações sociais efetuadas nos ambientes digitais, buscando enfatizar a noção de privacidade como aspecto não exclusivamente individual, mas eminentemente processual e relacional.

PALAVRAS-CHAVE: Privacidade; ambientes digitais; interações sociais.

\footnotetext{
${ }^{1}$ Doutor em Psicologia e Mestre em Gestão de Desenvolvimento Social. Atualmente é diretor de educação na ONG SaferNet Brasil. E-mail: rodrasn@gmail.com.

${ }^{2}$ Atualmente é Professor dos Programas de Pós-graduação em Psicologia (UFBA) e em Comunicação e Cultura Contemporâneas (UFBA). É coordenador do GITS - Grupo de Pesquisa em Interações, Tecnologias Digitais e Sociedade (UFBA/CNPQ) e professor colaborador do LAB404 Laboratório de Pesquisa em Mídia Digital, Redes e Espaço (UFBA/CNPQ). E-mail: jcsr01@gmail.com.
} 


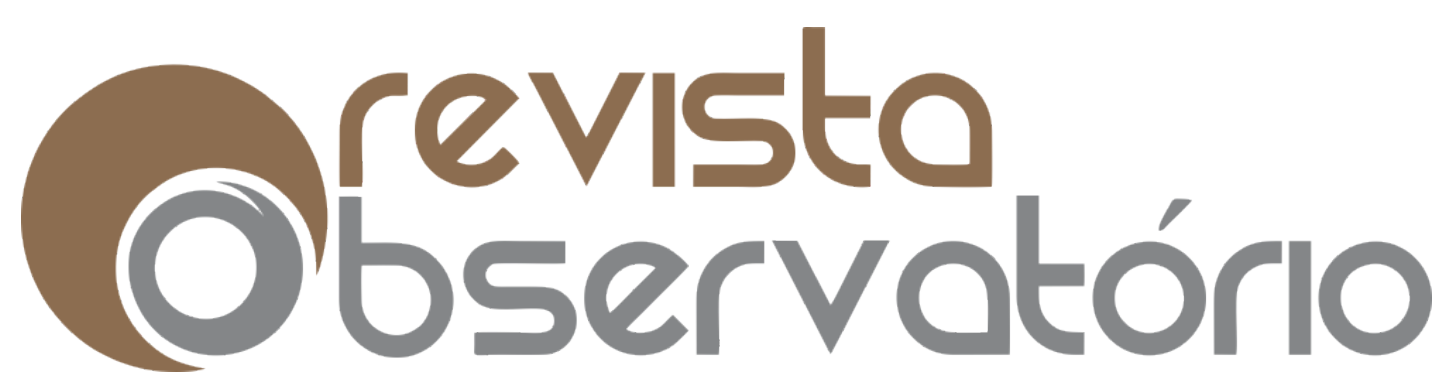

ISSN n² 2447-4266

Vol. 5, n. 5, Agosto. 2019

DOI: http://dx.doi.org/10.20873/uft.2447-4266.2019v5n5p111

\section{ABSTRACT}

This paper presents a brief discussion about the current challenges in the coordination of the limits of privacy in digital environments, in a plural dimension, with emphasis on the informational dimension, regarding the flow of personal information in social interactions carried out in digital environments, seeking to emphasize the notion of privacy as an aspect not exclusively individual, but eminently procedural and relational.

KEYWORDS: Privacy; digital environments; social interactions.

\section{RESUMEN}

Este trabajo presenta una breve discusión sobre los actuales desafíos en la coordinación de los límites de la privacidad en los ambientes digitales, en una dimensión plural, con destaque a la dimensión informacional, relativa al flujo de informaciones personales en las interacciones sociales efectuadas en los ambientes digitales, buscando enfatizar la noción de privacidad como aspecto no exclusivamente individual, sino eminentemente procesal y relacional.

PALABRAS CLAVE: Privacidad; Entornos digitales; Interacciones sociales.

Recebido em: 19.03.2019. Aceito em: 12.06.2019. Publicado em: 01.08.2019. 


\section{Observisto}

ISSN n² 2447-4266

Vol. 5, n. 5, Agosto. 2019

DOI: http://dx.doi.org/10.20873/uft.2447-4266.2019v5n5p111

\section{Reflexão inicial: a pluralidade da questão da privacidade}

$\mathrm{Na}$ atualidade, as discussões a respeito do fim da privacidade ocorrem simultaneamente aos esforços para garanti-la legalmente dentro e fora das relações nos ambientes digitais. A construção, desconstrução e reconstrução da própria noção de privacidade são questões basilares na formação das sociedades modernas (ELIAS, 1994; SENNET, 1999, SEVCENKO, 1998) e permanecem em mutação com as transformações sociais contemporâneas. Para uma breve discussão sobre os atuais desafios na coordenação dos limites da privacidade nos ambientes digitais, tomamos aqui o conceito de privacidade não como o oposto do público (no binário público x privado), mas como um conceito relacionado a um processo de regulação de limites interpessoais (DERLEGA \& CHAIKIN, 1977; WESTIN, 1967; ALTMAN \& TAYLOR, 1973; PETRONIO, 2002). Dentre a pluralidade de aspectos da privacidade, destacamos a dimensão informacional, mais precisamente ainda aquela relativa ao fluxo de informações pessoais.

Em suas considerações sobre o desafio de conceituar a privacidade, Solove (2002) aponta que mais produtivo do que propor uma definição de privacidade, precisamos de abordagens que permitam entender e analisar as dimensões de práticas relacionadas à privacidade, a partir de situações e contextos particulares. Em uma abordagem pragmática (SOLOVE, 2002), a privacidade está relacionada a diferentes práticas e aspectos da vida, englobando os espaços, as informações sobre si, limites de acesso ao self, segredos e relações íntimas, mas não pode ser reduzida a apenas um destes elementos para conceber uma definição geral e abstrata (SOLOVE, 2002). Para debater as questões relacionadas à privacidade nas interações sociais efetuadas nos ambientes digitais, parece-nos válido enfatizar a noção de privacidade como associada a um processo de controle sobre a dinâmica de preservação ou exposição de informações sobre si, sobre outros e sobre as relações (PETRONIO, 2002). Esta perspectiva, apesar de afastar-se de 


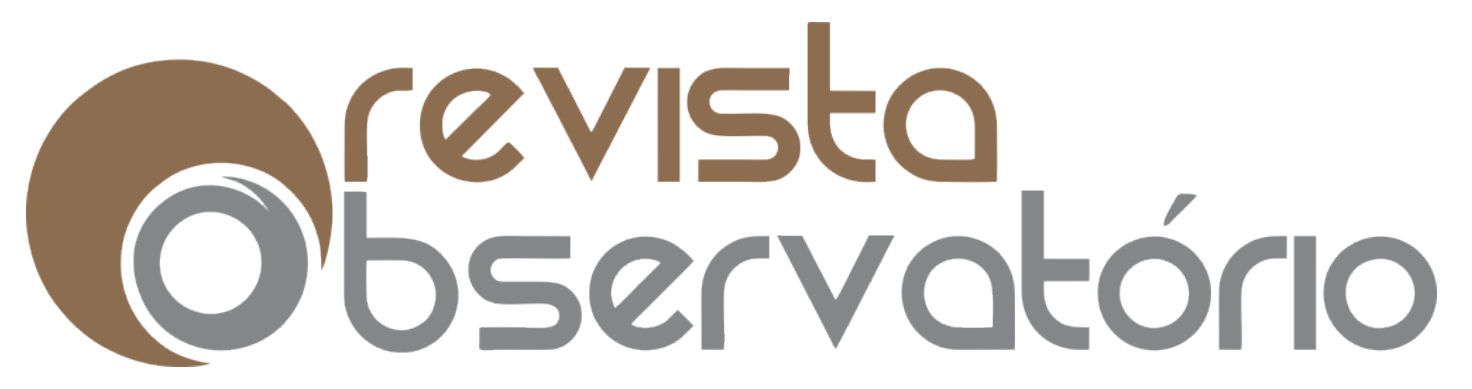

ISSN n² 2447-4266

Vol. 5, n. 5, Agosto. 2019

DOI: http://dx.doi.org/10.20873/uft.2447-4266.2019v5n5p111

outras dimensões da privacidade mais relacionadas às perturbações dos espaços pessoais e da autonomia para tomadas de decisões, ajuda-nos a enfatizar a noção de privacidade como aspecto não exclusivamente individual, mas eminentemente processual e relacional.

Ao analisarmos as interações sociais nos ambientes digitais, a dimensão informacional das questões de privacidade merece destaque ao considerarmos que as tecnologias digitais funcionam a partir das informações e com elas. Para criar um perfil em uma rede social, para instalar um aplicativo, para poder fazer uma compra online, para se cadastrar em um concurso ou vaga de emprego, precisamos oferecer um conjunto significativo de informações para diferentes instituições que as coletam, registram e utilizam de muitas maneiras para diferentes fins. Não apenas no ato do cadastro, mas na manutenção das conversações e interações sociais nos ambientes digitais precisamos seguir gerando e compartilhando nossos pensamentos, ideias, opiniões e posicionamentos através de informações que elegemos publicar.

Se a produção e compartilhamento desse grande volume de informações pessoais é algo evidente para muitos, a regulação dos limites de acesso às informações pessoais, o gerenciamento das regras de uso e a delimitação dos contextos nos quais as diferentes audiências acessam essas informações são aspectos menos evidentes e cada vez mais importantes nas interações sociais mediadas pelas tecnologias digitais. Se nas interações presenciais face a face (FF) a exposição e o registro das informações pessoais ficavam limitados aos recursos da memória dos participantes, as diferentes tecnologias de informação e comunicação gradativamente passaram reconfigurar as variáveis em jogo e as formas de administrar a visibilidade não apenas das informações sobre si, mas também das informações em geral (THOMPSON, 2011). 


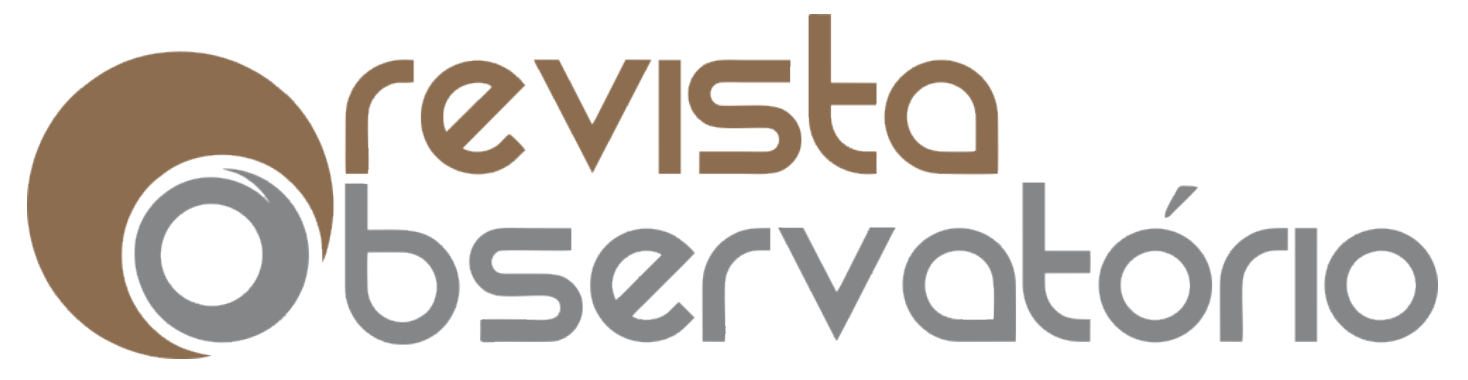

ISSN n² 2447-4266

Vol. 5, n. 5, Agosto. 2019

DOI: http://dx.doi.org/10.20873/uft.2447-4266.2019v5n5p111

Analisando as ressonâncias de algumas tecnologias digitais na coleta, processamento e análise de informações pessoais, Nissenbaum (2010) destaca a importância de pensarmos na privacidade sempre relacionada à integridade dos contextos de uso das informações pessoais, atentando mais para o fluxo apropriado destas informações do que apenas para o fato de elas serem ou não publicadas ou consideradas públicas. Nesta abordagem, o mais importante é compreender e esclarecer quais são as normas informacionais e os contextos nos quais as informações pessoais estão circulando (NISSENBAUM, 2010). Ao considerarmos ainda que a privacidade envolve uma relação dialética entre preservação e exposição, bem como a co-propriedade de informações, a mesma não pode ser reduzida à esfera individual (PETRONIO, 2002).

Enfatizar o aspecto relacional e processual da noção de privacidade nos parece muito útil para uma reflexão sobre os desafios de coordenação dos limites dos compartilhamentos de informações pessoais nos ambientes digitais. Uma vez revelada uma informação, o receptor assume responsabilidades individual ou coletivamente, criando expectativas de confiança por parte de quem expõe algo privado. As pessoas são simultaneamente receptoras e possuidoras de informações privadas de si e dos outros, implicando todos como atores na coordenação dos fluxos e delimitação dos contextos de uso destas informações (PETRONIO, 2002). Saber de informações privadas de alguém significa que há um potencial para revelar questões relativas a outros, implicando em uma copropriedade que traz uma obrigação implícita ou explicita para o receptor em relação à disseminação a terceiros (PETRONIO, 2002, 2010).

Esta noção de co-propriedade das informações privadas e o destaque para o fluxo apropriado das informações nos parecem aspectos valiosos para refletir sobre os diferentes contextos de compartilhamento de informações privadas nos ambientes digitais, quando lembramos que há diferentes formas de exposição e 


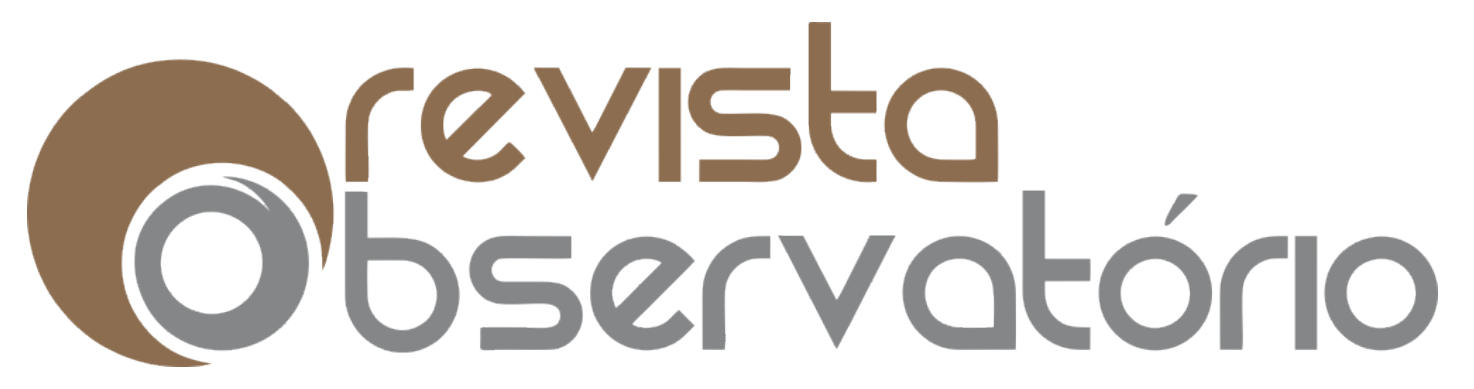

ISSN n² 2447-4266

Vol. 5, n. 5, Agosto. 2019

DOI: http://dx.doi.org/10.20873/uft.2447-4266.2019v5n5p111

de coleta de informações pessoais nestes ambientes. Destacando seu caráter dinâmico e relacional, com limites sempre negociados pelos e entre os indivíduos, precisamos estar atentos às formas como são construídas as regras que usamos para gerenciar a privacidade, individual e coletivamente, através das diferentes associações que fazemos ao interagir seja com outras pessoas ou com objetos.

Compartilhando privacidade: como coordenar a co-propriedade das informações pessoais nas redes digitais?

Se nos primeiros momentos da Internet as interações estavam baseadas no anonimato, favorecendo a manifestação de comportamentos até então inexplorados (TURKLE, 1995; WELLMAN, 2011; JOINSON \& PAINE, 2010), na atualidade muitos usuários usam intensamente os Sites de Redes Sociais e aplicativos sociais com seus nomes verdadeiros, expondo cotidianamente detalhes sobre suas vidas, incluindo endereços de onde estão, o que estão comendo, o que estão pensando, com quem estão em relacionamento (ou com quem querem vir a ter um), com quem possuem graus de parentesco, em quais instituições estudam e quais as preferências gerais em termos de lazer, além de expressarem suas opiniões sobre diferentes temas sociais e políticos pelos quais se interessam.

Interessa-nos destacar que quando falamos de exposição de informações pessoais nos ambientes digitais, precisamos lembrar que há diferentes estratégias e tipos de exposição. Assim como nas interações de co-presença física, nos diferentes contextos de interação social mediados precisamos selecionar e organizar aquilo que queremos comunicar aos nossos interlocutores (GOFFMAN, 1986). As formas como modelamos nossos comportamentos e nos apresentamos estão relacionadas ao repertório de referências identitárias que 


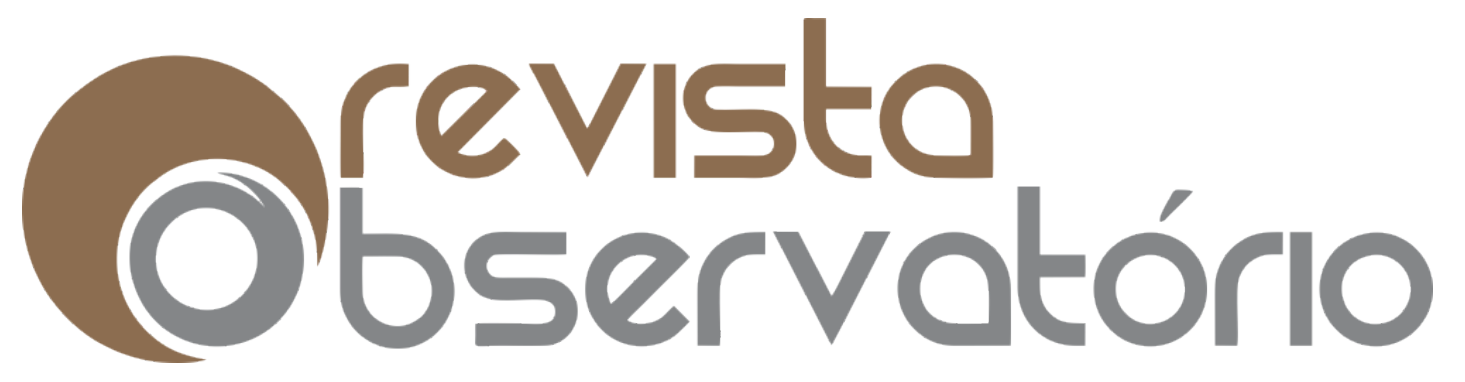

ISSN n² 2447-4266

Vol. 5, n. 5, Agosto. 2019

DOI: http://dx.doi.org/10.20873/uft.2447-4266.2019v5n5p111

servem de subsídio para nossas expressões, bem como às normas sociais de cada situação e as delimitações culturais sobre o que consideramos apropriado de expor nestas diferentes situações.

Para criar um perfil é preciso selecionar as informações a partir das quais o usuário quer se apresentar aos demais membros da rede, antes mesmo de iniciar suas conexões e relacionamentos. O processo de elaboração dos perfis nos SRS e a seleção de informações a serem expostas envolvem também um gerenciamento das impressões (GOFFMAN, 1986, 2011). Desde o cadastro, um processo complexo de controle sobre as estratégias de apresentação é disparado, pois cada escolha implica em impressões diferentes que serão geradas nos demais usuários da rede e servirão de referência para as próximas interações.

$\mathrm{Se}$ as primeiras pesquisas sobre a apresentação de si nos ambientes digitais indicavam o anonimato como fator de facilitação das experiências exploratórias do self e de múltiplas identidades desvinculadas das relações face a face (CHESTER \& BRETHERTON, 2007; TURKLE, 1995, RIBEIRO, 2010), atualmente os perfis nos SRS parecem convidar para formas de apresentação mais sintonizadas com as interações presenciais (BOYD, 2014; ELLISON, HEINO, \& GIBBS, 2006; ELLISON ET AL., 2011; O'HARA, 2010; MARWICK, 2010; ELLISON, 2010).

Mesmo havendo certa liberdade para falsear informações e controlar as apresentações na criação dos perfis nos SRS, as pesquisas indicam que gradativamente as relações estabelecidas através de SRS, como o Facebook, são avaliadas e monitoradas também com base nos diferentes contextos de interação presencial (HOGAN, 2010; TREOTE \& REINECKE, 2011).

Pensar nas formas de exposição de si como uma das formas de apresentação pessoal nas interações sociais remete a uma reflexão sobre as formas como os indivíduos percebem a si mesmos e se tomam como objetos 


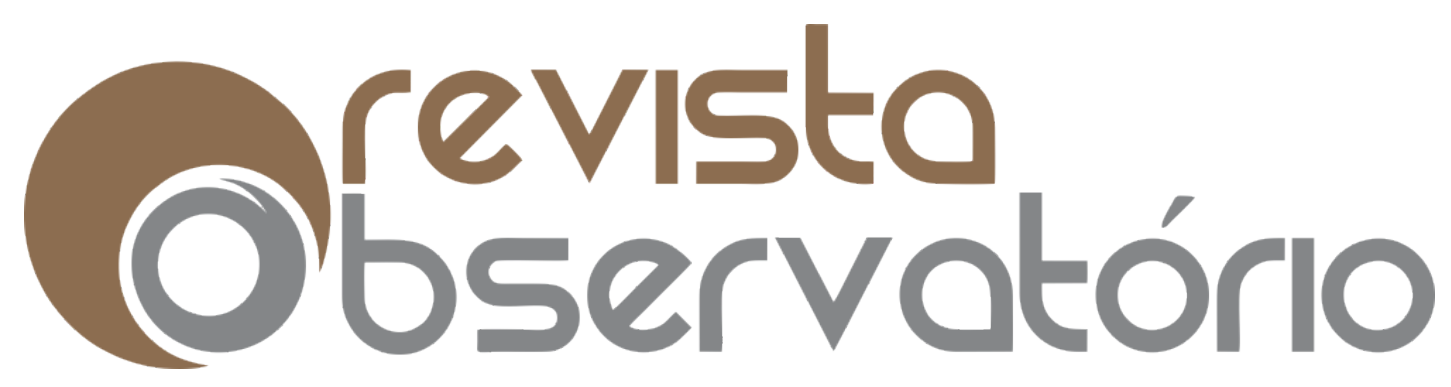

ISSN n² 2447-4266

Vol. 5, n. 5, Agosto. 2019

DOI: http://dx.doi.org/10.20873/uft.2447-4266.2019v5n5p111

para então estabelecer um relacionamento com os outros (SHLENKER, 2003). O uso dos SRS está condicionado ao fornecimento de informações pessoais. Porém, o processo de exposição das informações pessoais não está associado apenas às estratégias voluntárias de gerenciamento das impressões nas interações, e tampouco são parte de um processo exclusivamente individual. Consideramos que as exposições de si são resultantes de processos voluntários e involuntários, os quais costumam a ser efetivados de forma complementar.

Quando criamos um perfil em um SRS ou nos cadastramos em um aplicativo que favorece trocas e encontros interpessoais, precisamos selecionar as informações pessoais que queremos compartilhar e 0 fazemos voluntariamente. O mesmo quando realizamos uma compra em uma loja digital ou realizamos uma pesquisa em um site de buscas. Precisamos publicizar de alguma forma nossas questões e informações para que tenhamos os retornos esperados nestas diferentes práticas na rede. Dos usuários mais interessados em registrar e compartilhar o máximo de detalhes sobre suas vidas, como os adeptos do quantified self ${ }^{3}$ (BRUNO \& NASCIMENTO, 2013), ao usuário esporádico que conversa com amigos e familiares na rede, um volume considerável de informações pessoais é compartilhado nos ambientes digitais.

Além dessas exposições voluntárias nos diferentes SRS e aplicativos, não podemos menosprezar o volume de dados e metadados ${ }^{4}$ que as empresas

\footnotetext{
3 Pessoas que aderem ao uso e desenvolvimento de dispositivos sensorizados, softwares, plataformas colaborativas online, aplicativos para celular e outras ferramentas para registrar e monitorar suas ações cotidianas e descobrir tendências e correlações sobre seu comportamento e sua saúde a partir do armazenamento, a longo prazo, de diversos conjuntos de indicadores que permitem monitorar uma infinidade de condições: doenças crônicas, atividade sexual, qualidade do sono, humor, produtividade, uso do tempo, performance cognitiva, atividade física etc. (Nascimento \& Bruno, 2013).

${ }^{4}$ Meta-dados podem ser basicamente definidos como "dados que descrevem os dados", ou seja, são informações úteis para identificar, localizar, compreender e gerenciar os dados (IBGE). Consultado em: http://www.metadados.ibge.gov.br/consulta/glossario.aspx?letra=M
} 


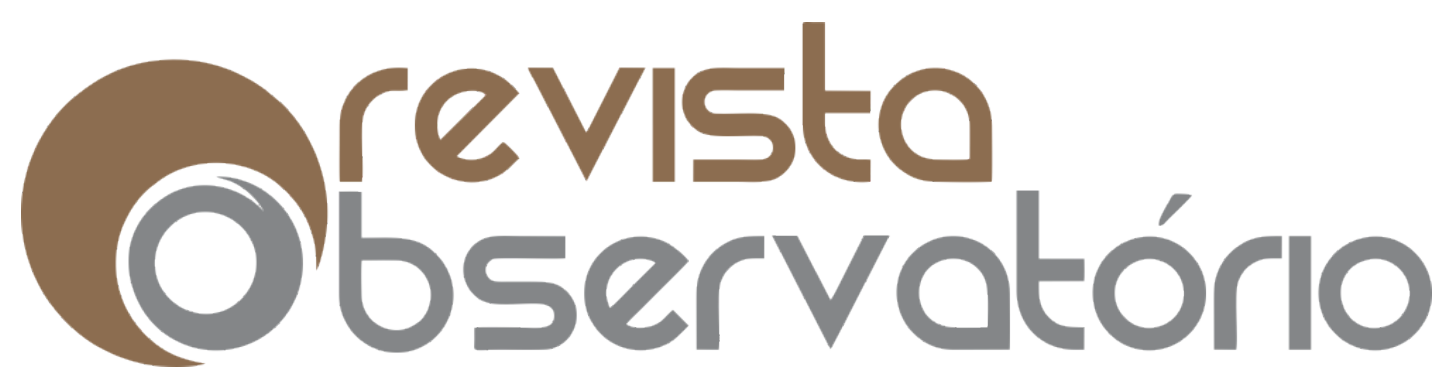

ISSN n² 2447-4266

Vol. 5, n. 5, Agosto. 2019

DOI: http://dx.doi.org/10.20873/uft.2447-4266.2019v5n5p111

proprietárias dos serviços coletam sobre as interações nos ambientes digitais, muitas vezes agregando detalhes da vida do usuário que ele próprio desconhece ou não possui condições de perceber. Neste caso, estamos lidando com uma exposição involuntária ou não esclarecida, já que, apesar de esta coleta estar comumente prevista nos Termos de Uso dos sites, dificilmente são consideradas pelos usuários. Ao aceitar as regras de uso do Facebook, por exemplo, os usuários aceitam em compartilhar com a empresa cerca de 70 tipos de dados sobre seus usos, tais como: a descrição detalhada sobre as conversas realizadas na ferramenta de bate-papo privado; todas as informações sobre o tipo de navegador, local de conexão, modelo do aparelho; a lista de todos os cliques em anúncios; a lista detalhada de todas as ações de curtir e compartilhar; os textos dos cometários realizados no próprio perfil e nos demais, dentre outros 5 .

A forma de funcionamento dos algoritmos que selecionam os conteúdos que serão apresentados nas atualizações dos perfis dos SRS, por exemplo, é baseada em um conjunto de regras que, na maior parte dos casos, escapam da compreensão dos usuários, mesmo que tenham consentido com elas no ato de registro no serviço. A validade e efetividade do consentimento das regras de uso dos dados pessoais dos principais serviços online é questionável inclusive legalmente, assim como o autogerenciamento da privacidade nestes sites e aplicativos, já que a capacidade de negociação e agência dos usuários é bastante desproporcional com relação àquela das empresas envolvidas (SOLOVE, 2012).

\footnotetext{
${ }^{5}$ Para conferir a lista completa de dados e meta-dados coletados pelo Facebook, basta acessar a página explicativa sobre as formas de usos dos dados. A empresa disponibiliza atualmente uma opção para o usuário baixar uma cópia de parte destes dados e meta-dados que estão registrados nos servidores da empresa, fruto de complexas batalhas judiciais relacionadas à lei de proteção aos dados pessoais, principalmente na Europa. Mais detalhes sobre a lista de dados e as regras de uso do site estão no próprio Facebook: https://www.facebook.com/help/405183566203254
} 


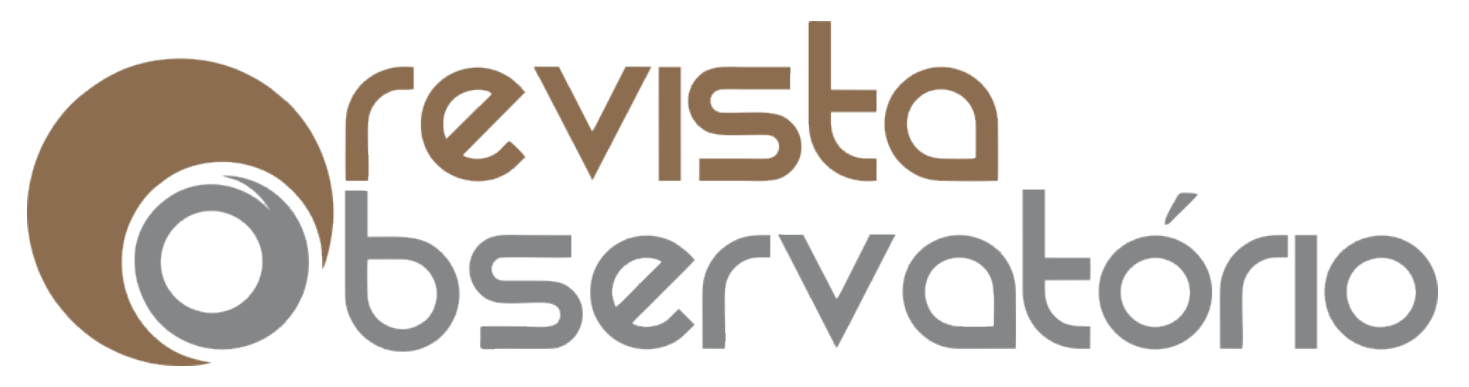

ISSN n² 2447-4266

Vol. 5, n. 5, Agosto. 2019

DOI: http://dx.doi.org/10.20873/uft.2447-4266.2019v5n5p111

O mesmo ocorre no filtro das pesquisas em sites de busca como o Google e o Bing ${ }^{6}$, gerando uma dinâmica particular de articulação de conteúdos para visualização, denominada por Pariser (2011) como "filtro bolha", o que pode limitar os resultados apenas às informações já familiares aos usuários, afastando a probabilidade de encontrar conteúdos e informações muito diferentes daquelas previamente acessadas pelo próprio usuário e seus círculos de relacionamento preferidos nos ambientes digitais.

O conjunto de informações expostas involuntariamente ou indiretamente geram um tipo singular de relacionamento entre os usuários e as empresas proprietária dos serviços, no qual não parece haver reciprocidade nem gradação no fornecimento de informações mais íntimas, já que o fornecimento de boa parte destes dados e metadados é compulsório da parte do usuário. O mesmo poderíamos dizer sobre os sistemas de vigilância massiva das comunicações digitais que permitem acesso, registro, monitoramento e análise em escala global das informações pessoais dos usuários dos serviços mais populares na Internet, conforme revelações recentes feitas pelo ex-agente da Agência Nacional de Segurança dos Estados Unidos (NSA - National Security Agency), Edward Snowden?.

Ainda em relação ao registro e fluxo de informações pessoais feitos de maneira involuntária, não podemos deixar de destacar o uso que nossas redes de amigos, familiares e conhecidos fazem a partir daquilo que publicamos em SRS ou em aplicativos de compartilhamento de informações. A partir do momento em que compartilhamos uma foto, um vídeo, um comentário ou qualquer outro arquivo digital, aqueles que o recebem passam a ser co-proprietários e passam a

\footnotetext{
6 www.google.com e www.bing.com

7 Ver informações mais detalhadas sobre este caso em http://www.theguardian.com/usnews/the-nsa-files
} 


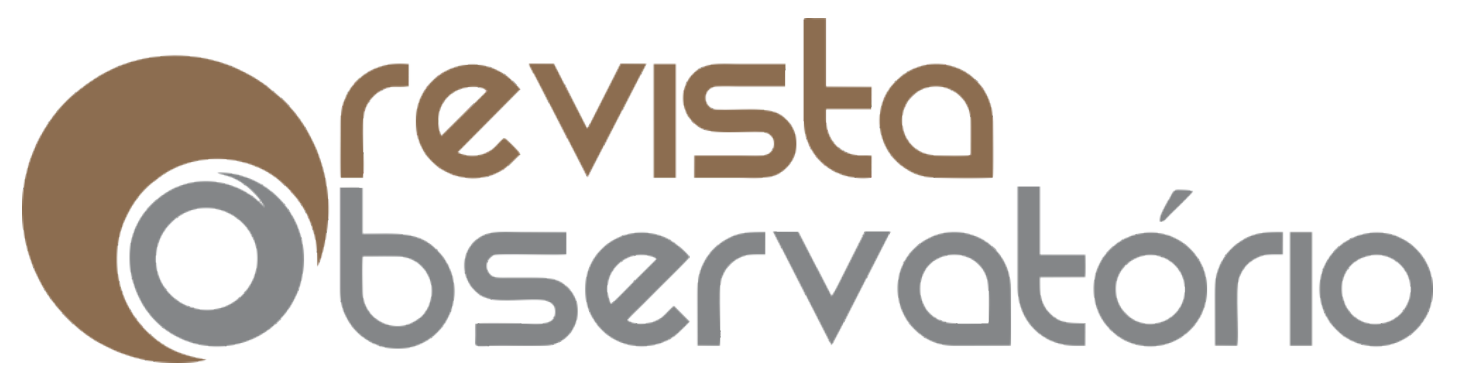

ISSN n² 2447-4266

Vol. 5, n. 5, Agosto. 2019

DOI: http://dx.doi.org/10.20873/uft.2447-4266.2019v5n5p111

ter poder na regulação do fluxo destas informações, bem como na delimitação dos contextos de uso delas (PETRONIO, 2010).

Neste sentido, não podemos deixar de considerar as informações privadas como elementos que estão sempre em estado de co-propriedade, uma vez compartilhadas voluntária ou involuntariamente. No caso dos serviços online de e-mail e em redes como Facebook, inclusive parte das publicações que os usuários começam a escrever e desistem de publicar ficam registradas nos servidores das empresas para pesquisas e análises futuras sobre os comportamentos de auto-censura (DAS \& KRAMER, 2013; SLEEPER ET AL., 2013).

A coordenação das regras de privacidade e a delimitação dos usos das informações privadas são aspectos que precisam ser pensados de forma a integrar estas diferentes variáveis, especialmente quando consideramos as desigualdades de poder e de conhecimento entre os atores envolvidos e suas implicações. Mesmo que os usuários conheçam e usem os mecanismos de privacidade dos sites que frequentam, dificilmente têm poder de participar de sua criação ou alteração, sendo que os critérios para a aplicação das regras de gerenciamento da privacidade escapam quase sempre de seu controle. Podemos considerar que as regras de seleção de conteúdos e de audiências para as exposições são adquiridas de forma compulsória ao aceitarmos os termos de uso do site na ocasião do cadastro, mesmo que haja a opção de gerenciar alguns dos limites de visibilidade posteriormente. O mesmo raciocínio podemos aplicar quando pensamos na questão da vigilância massiva praticada por governos e agências de segurança, trazendo à tona sérias implicações sobre os direitos ao anonimato, liberdade de expressão e autonomia para fazer escolhas de consumo, posicionamento ideológico e de associação, dentre outros.

Para esta nossa breve reflexão, interessa-nos destacar o quanto a negociação das regras de privacidade dependem da articulação das diferentes 


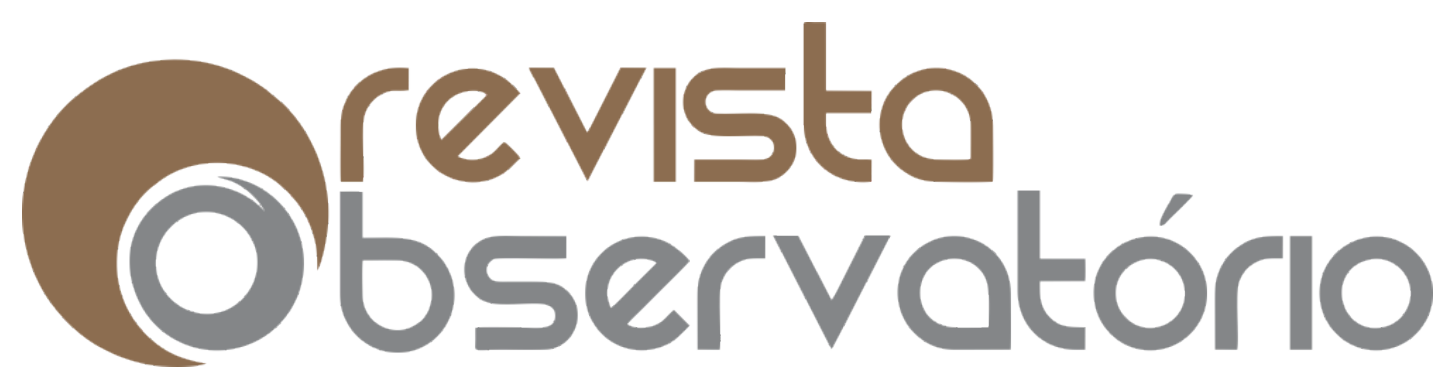

ISSN n² 2447-4266

Vol. 5, n. 5, Agosto. 2019

DOI: http://dx.doi.org/10.20873/uft.2447-4266.2019v5n5p111

relações de poder, expectativas e valores culturais dos atores envolvidos, evidenciando novamente o quanto as questões de privacidade são indissociáveis dos costumes e normas sociais mais amplas, dependendo sempre dos contextos e das práticas gerais consideradas apropriadas e convenientes. A articulação das agências dos usuários, seus pares, dispositivos, algoritmos e contextos mostra-se vital para compreendermos a demilitação das regras de privacidade nas práticas cotidianas atuais, práticas que geram e provocam negociações entre as diferentes regras orientadoras disponíveis, estabelecendo rotinas híbridas e novas formas de sanção às violações efetivadas.

\section{Expectativas e referências orientadoras sobre o fluxo das informações privadas}

Ao considerarmos as exposições voluntárias de informações privadas, um dos muitos desafios observados é a dificuldade de manejar as audiências que terão acesso às informações publicadas nos ambientes digitais. Por mais que tenhamos em mente uma audiência imaginada (BOYD \& MARWICK, 2011) e destinatários prioritários (PETRONIO, 2002) ao compartilharmos informações pessoais, os ambientes digitais possuem singularidades enquanto espaços interacionais ao evidenciarem dinâmicas de audiências invisíveis, contextos colapsados e a fluidez entre público e privado (BOYD, 2011).

Especialmente nos SRS, a intensidade e o volume de interações sociais dão origem a um tipo específico de multidão, a exemplo do que pesquisadores apontam como "aglomeração digital" (JOINSON, 2011). Assim como outras multidões, as aglomerações digitais diminuiriam as habilidades de controlar as interações, particularmente as fronteiras entre o self, os pequenos grupos íntimos, e as audiências mais públicas. Este novo tipo de aglomeração seria fruto da perturbação da regulação dos limites nas interações sociais, permitindo múltiplas audiências - com métodos limitados de controle dos limites - e 


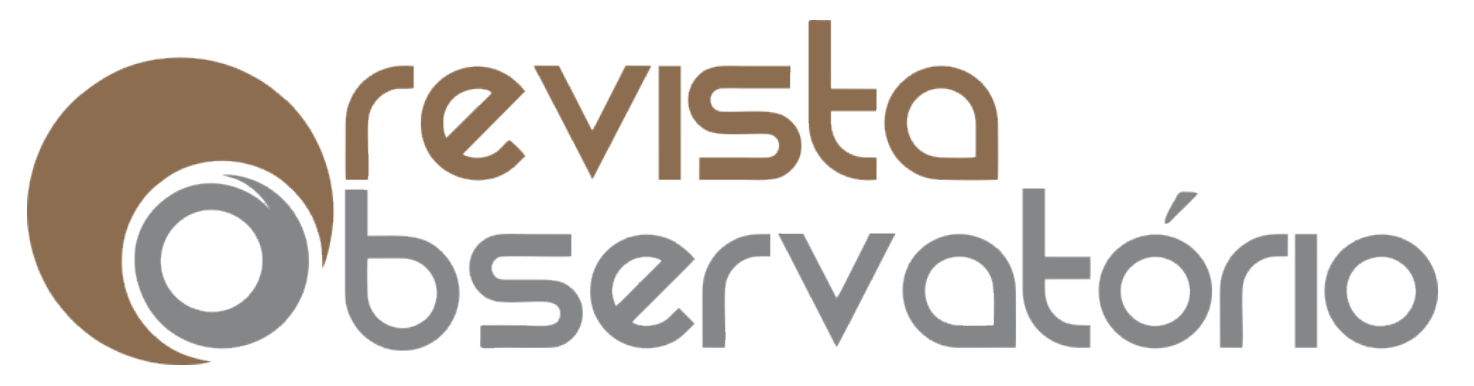

ISSN n² 2447-4266

Vol. 5, n. 5, Agosto. 2019

DOI: http://dx.doi.org/10.20873/uft.2447-4266.2019v5n5p111

encorajando o compartilhamento irrestrito de informações pessoais que implicam outros usuários (JOINSON, 2011).

Para Joinson (2011), a "aglomeração digital" (excesso de contato e de compartilhamento) pode ser prejudicial à privacidade e à qualidade dos relacionamentos estabelecidos ao menos de duas formas: (1) através do perigo inerente na transparência radical ou na abertura irrestrita; e (2) através da sobreposição das esferas sociais e da falta de habilidade dos usuários para manejar limites/bordas extremamente dinâmicas. Diante dessa proposição, não podemos deixar de considerar que há uma adesão voluntária para a exposição de si e para o consumo das exposições dos outros, adesão que é estimulada pelos benefícios diretos ou potenciais que são esperados em troca destas exposições. Concordando que a preservação de informações privadas e o segredo também são importantes no desenvolvimento dos relacionamentos, acreditamos que as práticas de exposição de si indicam mais um processo criativo de renegociação sobre as regras de privacidade do que apenas uma perturbação daquelas estabelecidas com base apenas nas relações presenciais. Compartilhar informações nos ambientes públicos não se reduz obrigatoriamente à exposição de questões íntimas ou informações privadas, mesmo que a exposição traga benefícios para a ampliação da rede de relacionamento e ganho de capital social (ELLISON et al., 2011).

Cada vez mais é difícil manejar os limites e negociar (ou aceitar) as normas de comportamento de cada esfera social, considerando que as exposições ocorrem para audiências invisíveis e imaginadas (MARWICK e BOYD, 2011; HOGAN, 2010). Se temos múltiplas audiências, cada uma com suas normas e convenções sobre que tipo de exposição é considerada apropriada, o tempo e os esforços exigidos para negociar os compartilhamentos atendendo a todas as normas e expectativas são demasiadamente grandes para serem satisfeitos em 


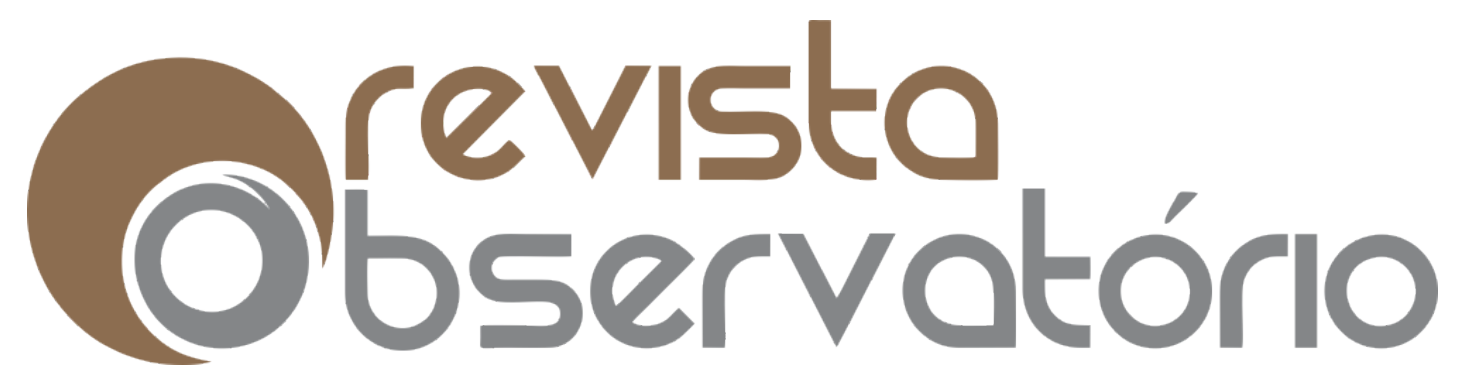

ISSN n² 2447-4266

Vol. 5, n. 5, Agosto. 2019

DOI: http://dx.doi.org/10.20873/uft.2447-4266.2019v5n5p111

todas as ocasiões. Outro fator é que os amigos conectados nos SRS não são apenas aqueles de confiança, com os quais já acordamos regras e expectativas de forma implícita ou explícita sobre os usos apropriados das informações compartilhadas. Na relação com os amigos menos próximos, nem sempre há regras e expectativas estabelecidas previamente para coordenar os limites da privacidade, ou, caso existam, estas costumam se mostrar menos definidas e menos baseadas em normas sociais de comportamento habituais (JOINSON et al, 2011).

Questionamos até que ponto estes contextos colapsados (BOYD \& MARWICK 2011), ou as esferas sociais sobrepostas - nos termos de Binder (2009), também não passam a ser apropriados levando em consideração novas convenções, específicas e contextualizadas para estes ambientes semi-públicos, como o Facebook. Podemos dizer que os usuários dos SRS, vivenciando este caráter múltiplo e plural, contemplando o íntimo e o distante, criam estratégias para que suas exposições sejam dosadas a partir da negociação de regras contextuais singulares, partindo de um desejo de consumo de fatos e situações da esfera do privado, sejam eles oriundos das experiências particulares ou daquelas propiciadas pelos outros. Se as informações privadas são eminentemente co-propriedade e não apenas propriedade individual, as pessoas se sentem no direito de se apropriarem daquilo que foi publicado de acordo com suas regras e expectativas relacionadas às particularidades contextuais.

A hipótese de alguns pesquisadores, como Joinson (2011), é de que a falência dos mecanismos de privacidade online, e o design dos sites que permitem a aglomeração digital, resultariam em estresse e eventual afastamento nas relações ao facilitar com que os espaços pessoais sejam tão violados na aglomeração digital como o são na multidão em um evento presencial face a face. A esse respeito, vale ressaltar que o design dos SRS e as regras de uso dos 


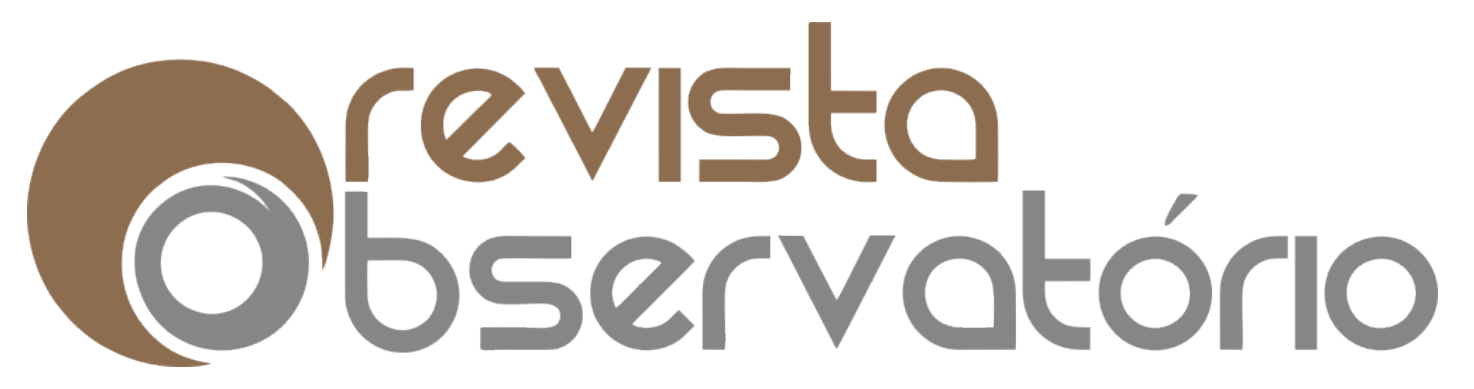

ISSN n² 2447-4266

Vol. 5, n. 5, Agosto. 2019

DOI: http://dx.doi.org/10.20873/uft.2447-4266.2019v5n5p111

dados pessoais são fatores que não existiam nas multidões nas ruas e nas praças. Antes do desenvolvimento das tecnologias digitais era tecnicamente inviável rastrear os movimentos de cada pessoa em uma multidão, assim como impraticável saber qual a opinião de cada sujeito sobre os temas difusos que provocaram a reunião daqueles presentes.

O próprio anonimato possível em uma multidão presencial face a face apresenta-se radicalmente transformado nas interações em SRS, como o Facebook, que operam através do registro detalhado de cada ação dos usuários. Ao mesmo tempo, assistimos a uma supervalorização da exposição das intimidades e uma busca gradativa por mais informações pessoais nos diferentes meios, espetacularizando as diversas e múltiplas intimidades (SIBILIA, 2008). Fim dos limites ou criação de novos referenciais para a compreensão do
fenômeno da privacidade?

Para além do discurso de pânico moral que antecipa (e promove) uma suposta morte da privacidade, esta discussão merece ser ampliada para que possamos melhor visualizar as transformações de nossa época. Muito além do que apontar o fim dos limites privados, parece-nos vital prestar uma atenção maior para estes limites imaginários que criamos justamente para dar sentido a - também socialmente construída - diferenciação dos espaços públicos e privados. Podemos dizer que historicamente a arquitetura e a geografia ancoravam os limites de exposição de uma conversa, de um ato ou performance.

As paredes e as distâncias faziam mais nítidas as segregações de públicos e de contextos. A altura da voz, a escolha dos interlocutores, a escolha do "lugar certo" para "certos assuntos", a codificação da escrita e das mensagens eram algumas das maneiras possíveis de gerenciar os limites e os graus de exposição de si (e da relação) a partir dos referenciais de tempo e espaço geográficos. Já nas interações que ocorrem nas redes digitais, vale destacar que se antes os 


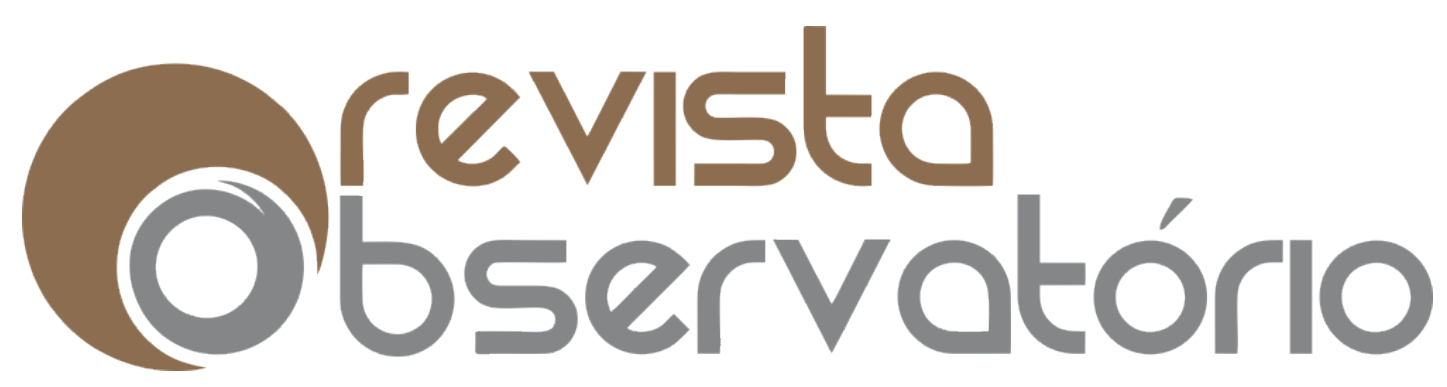

ISSN n² 2447-4266

Vol. 5, n. 5, Agosto. 2019

DOI: http://dx.doi.org/10.20873/uft.2447-4266.2019v5n5p111

conteúdos compartilhados nas interações eram privados por padrão, agora são públicos por padrão e privados através de esforço (BOYD, 2014). Esta afirmação nos parece muito pertinente e aplicável quando comparamos os limites arquitetônicos e geográficos com os limites fluidos e dinâmicos das redes digitais.

Ampliando esta reflexão sobre privacidade para considerar os limites negociados coletivamente, parece fundamental tentar unificar, nas análises sobre os usos e apropriações, estes diferentes elementos em jogo, os quais incluem: as singularidades técnicas dos networked publics ${ }^{8}$ (BOYD, 20111), os termos de privacidade dos serviços, as políticas das empresas em relação à vigilância governamental, as motivações pessoais, as dinâmicas da comunicação interpessoal e as mudanças culturais de valorização do prática e consumo da exposição de si.

Na dinâmica de interação em rede, as camadas não aparentam ser tão lineares e a privacidade parece ser uma composição polimorfa de pontos, de agregações provisórias que formam limites provisórios, em interações provisórias, reconstituindo-se a cada interação ou contexto, ajustando-se com regras também provisórias ou desagregando-se com as eventuais turbulências que emergem das trocas efetivadas. Esta nos parece a configuração que se apresenta atualmente. A compreensão destes aspectos e particularidades é que se constitui o nosso maior desafio enquanto pesquisadores da área.

\footnotetext{
${ }^{8}$ Com esta noção, a autora aponta a peculiaridade do público reestruturado pelas tecnologias digitais em rede, destacando duas características simultâneas: (1) trata-se de um público construído através das tecnologias digitais em rede e (2) formado a partir de uma coletividade imaginada que emerge como um resultado da interseção entre pessoas, tecnologias e práticas (Boyd, 2011, p.39).
} 


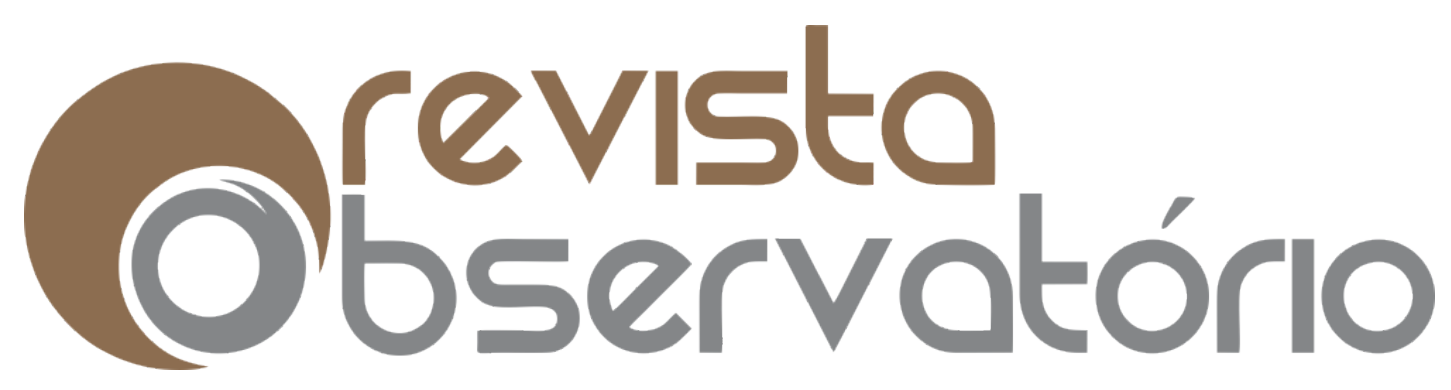

ISSN n² 2447-4266

Vol. 5, n. 5, Agosto. 2019

DOI: http://dx.doi.org/10.20873/uft.2447-4266.2019v5n5p111

\section{Referências}

ALTMAN, I., \& TAYLOR, D. A. Social penetration. The development of interpersonal relationships. New York: Holt, Rinehart and Winston, 1973.

DAS, S., \& KRAMER, A. Self-Censorship on Facebook. In Seventh International AAAl Conference on Weblogs and Social Media. Disponível em: http://www.aaai.org/ocs/index.php/ICWSM/ICWSM13/paper/view/6093, 2013.

ELIAS, N. O processo civilizador: uma história dos costumes v I. Rio de Janeiro: Jorge Zahar, 1994.

O processo civilizador: Formação do Estado e Civilização v. II. Rio de Janeiro: Jorge Zahar, 1993.

GOFFMAN, E. Ritual de interação: ensaios sobre o comportamento face a face. Petrópolis: Vozes, 2011.

JOINSON, A. N., \& PAINE, C. B. Self-disclosure, privacy and the Internet. In Joinson, A. N. The Oxford Handbook of Internet Psychology (pp. 237-252). Oxford: Oxford University Press, 2010.

JOINSON, A. N. Digital Crowding: Privacy, Self-Disclosure, and Technology. In Trepte, S. \& Reinecke, L. (Eds.). Privacy online: Perspectives on privacy and selfdisclosure in the social web. New York: Springe, 2011.

JOURARD, S. M.. Some psychological aspects of privacy. Law and Contemporary Problems, 3J, 307-318, 1966.

MARGULIS, S. T. Three Theories of Privacy: An Overview. In Treote, S., Reinecke, L. (Ed.). Privacy Online: Perspectives on Privacy and Self-Disclosure in the Social Web. Springer, Berlin, 2011.

NASCIMENTO, L. C., BRUNO, F. G. Quantified Selves: contar, monitorar e conhecer a si mesmo através dos números. In: XXII Encontro Anual da Compós, UFBA, 2013.

RIBEIRO, J. C. The increase of the experiences of the self through the practice of multiple virtual identities. PsychNology, v. 7, p. 291-302, 2010.

SCHLENKER, B. R.. Self-presentation. In Leary, M. R., \& Tanney, J. P. (ed.)(2003) Handbook of Self and Identity (492-518). New York: The Guilford Press, 2003.

SENNETT, R. O Declínio do Homem Público: as tiranias da intimidade. São Paulo: Companhia das Letras, 1999. 


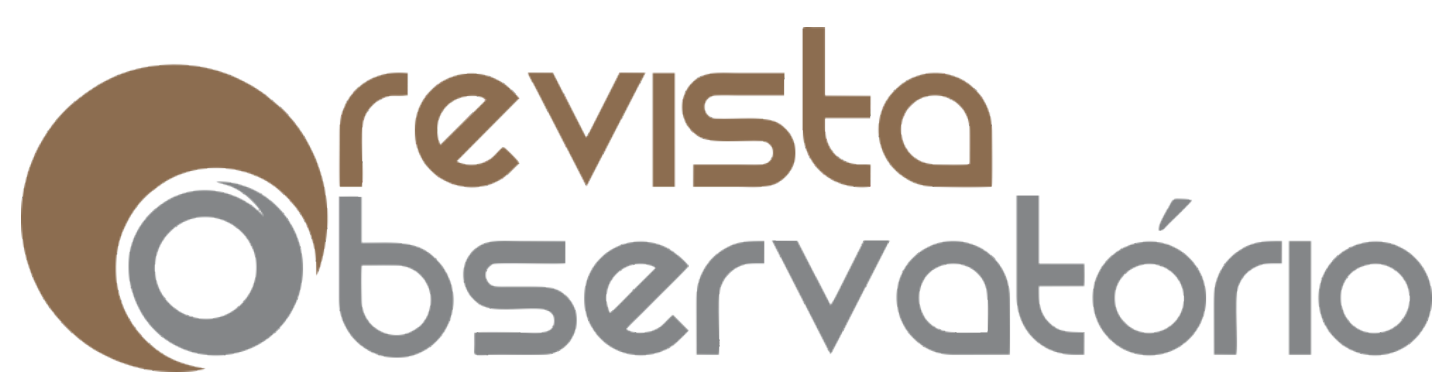

ISSN n² 2447-4266

Vol. 5, n. 5, Agosto. 2019

DOI: http://dx.doi.org/10.20873/uft.2447-4266.2019v5n5p111

SEVCENKO, N. História da vida privada no Brasil. Vol. 4. São Paulo: Companhia das Letras, 1998.

SIBILIA, P. O show do eu: a intimidade como espetáculo. Rio de Janeiro: Nova Fronteira, 2008.

SLEEPER, M., BALEBAKO, R., DAS, S., MCCONAHY, A. L., WIESE, J., \& CRANOR, L. F. (2013). The Post That Wasn'T: Exploring Self-censorship on Facebook. In Proceedings of the 2013, Conference on Computer Supported Cooperative Work (pp. 793-802). New York, NY, USA: ACM.

SOLOVE, D. J. Conceptualizing Privacy. California Law Review, 90, 1087-1156, 2002..

D. J. Privacy Self-Management and the Consent Dilemma. Rochester, NY:
Social Science Research N Network. Disponível em:
http://papers.ssrn.com/abstract=2171018, 2012.

THOMPSON, J. B. A mídia e a modernidade. Petrópolis, RJ: Vozes, 2009. 